\title{
Técnica de valoração econômica de ações de requalificação do meio ambiente: aplicação em área degradada
}

\section{Economic appraisal technical of re-qualification actions of the environment: application in degraded area}

\begin{abstract}
Ailson Oldair Barbisan
Engenheiro Civil. Mestre em Engenharia pela Universidade de Passo Fundo (UPF). Professor da Universidade do Oeste de Santa Catarina (Unoesc),

Curso de Arquitetura e Urbanismo, disciplinas de Geologia Ambiental, Instalações Hidrossanitárias, Legislação e Incorporação
\end{abstract}

\section{Adalberto Pandolfo}

Engenheiro Civil. Professor Doutor pelo Programa de Pós-Graduação em Engenharia (PPGENG) da UPF

Renata Reinehr

Estudante de Engenharia Civil. Bolsista Pibic/CNPq da Faculdade de Engenharia e Arquitetura (Fear) da UPF

\section{Marcele Salles Martins}

Arquiteta e Urbanista. Mestranda na área de Infraestrutura e Meio Ambiente da UPF

\section{Luciana Marcondes Pandolfo}

Engenheira Civil. Doutoranda do Programa de Pós-Graduação em Engenharia na Universidade Federal do Rio Grande do Sul (UFRGS).

Professora da disciplina de Materiais de Construção da Faculdade de Engenharia e Arquitetura da UPF

\section{Jalusa Guimarães}

Estudante de Engenharia Civil. Bolsista Pibic/UPF da Faculdade de Engenharia e Arquitetura da UPF

\section{José Waldomiro Jiménez Rojas}

Engenheiro Civil. Doutorando em Engenharia Civil (Geotecnia) na UFRGS. Professor das disciplinas de Geotecnia e Estruturas

de Fundações do Centro Universitário Metodista (IPA)

\section{Resumo}

O objeto de estudo deste trabalho foi uma área junto ao Rio Passo Fundo, na cidade de Passo Fundo, RS, ocupada irregularmente com moradias de caráter precário, em locais de risco e sujeitos a inundação. Após a caracterização da área objeto de estudo, foi aplicado o Método da Avaliação Contingente, através da técnica de Disposição a Pagar (DAP), para valoração econômica de possíveis intervenções urbanísticas e ambientais. Foram aplicados questionários em três grupos de moradores do entorno da área ocupada, visando avaliar a sua disposição a pagar pela requalificação da mesma. Os resultados obtidos demonstraram a viabilidade da aplicação do Método da Avaliação Contingente, considerando-se diferentes condicionantes ambientais, notadamente no que se refere à valoração econômica de um passivo ambiental.

Palavras-chave: valoração econômica; sustentabilidade ambiental; gestão urbana.

\section{Abstract}

The objective of study of this paper was an area next to the river Passo Fundo, in the city of Passo Fundo, RS, irregularly occupied with dwellings of precarious character in localities of risk and subjected to the flood. After characterization of the study area, the Method of Contingent Evaluation was applied through the technical of Disposition to Pay (DTP), for economic appraisal of possible environmental and urban planning interventions. Questionnaires were applied in three groups of inhabitants that lived around the mentioned area, aiming at evaluate their disposition to pay for its requalification. The results obtained gave evidence of the feasibility of the Method of Contingent Evaluation application, considering different environmental conditions, particularly referring to the economic assessment of a passive environmental.

Keywords: economic appraisal; environmental sustainability; urban management. 


\section{Introdução}

Durante muitos anos foram adotadas políticas públicas municipais de desenvolvimento urbano sem que os aspectos ambientais relacionados ao planejamento urbano fossem considerados, pelo fato de que as políticas ambientais centralizam-se nos órgãos estaduais e federais.

Entretanto, a variável ambiental tem assumido gradativamente um papel relevante na orientação de futuras políticas de gestão urbana, principalmente em função da legislação vigente e das ações de órgãos governamentais e não-governamentais, o que evidencia a importância desse tema. A partir da Conferência das Nações Unidas sobre o Meio Ambiente e Desenvolvimento, realizada no Rio de Janeiro em 1992 (a Eco 92), estipulou-se um pacto pela mudança do padrão de desenvolvimento global para o século 21 denominado Agenda 21. No Brasil, os trabalhos realizados para elaboração da Agenda 21 levaram a um amplo diagnóstico, com destaque para o agravamento dos problemas urbanos e ambientais das cidades em função dos adensamentos desordenados, da carência de recursos e de planejamento urbano e, também, de padrões inadequados de gestão (ROSSETO, 2003).

Ao longo dos últimos 50 anos, o crescimento desordenado da cidade de Passo Fundo e a consequente ocupação irregular de áreas insalubres e ribeirinhas, dentre elas a área objeto de estudo, ocasionou uma série de impactos ambientais. Esses impactos ocorreram devido à devastação de matas nativas e ciliares (resultado da atividade econômica de extração e beneficiamento de madeira, prática característica do período inicial de expansão urbana do município), agravados, posteriormente, pelo assoreamento dos leitos dos rios e córregos localizados no perímetro da malha urbanizada e pela poluição causada pelo esgoto e lixo doméstico.

Nas décadas de 1970 e 1980, com o surgimento da legislação federal que regulamenta a ocupação do solo urbano e da legislação ambiental, a atividade de implantação de novos loteamentos passou a ser fiscalizada pelo poder público municipal.

No município de Passo Fundo, o Plano Diretor (lei no 744 de 12 de junho de 1957) estabeleceu sugestões para que áreas ocupadas irregularmente, possuindo a mesma configuração da área em estudo, tivessem algum tipo de tratamento paisagístico. O objetivo dessa lei era a preservação dessas áreas através da implantação de vias de circulação e um parque público ao longo das margens do Rio Passo Fundo. Esse objetivo não foi observado pela administração pública, apesar dos estudos realizados para a formulação da segunda edição do Plano Diretor de Desenvolvimento Urbano - PDDU (lei n 2133 de 13 de dezembro de 1984) no ano de 1983, período em que a área objeto de estudo encontrava-se em fase de ocupação.

Sob esse enfoque, esta pesquisa estabelece parâmetros de sustentabilidade por meio da aplicação do Método de Valoração Econômica da Avaliação Contingente, que contribui para uma gestão ambiental mais adequada. Verifica-se a viabilidade de implantação de políticas de gerenciamento da ocupação do solo urbano e da preservação do meio ambiente, identificando a disposição das pessoas a pagar para recuperação de áreas degradadas, sistematizando, assim, uma discussão dos resultados obtidos frente à realidade local.

\section{Gestão ambiental}

A gestão ambiental, de acordo com Maimon (1996), tanto no âmbito empresarial quanto na gestão pública, torna-se uma ferramenta significativa na criação de condições socioeconômicas de sustentabilidade e atendimento das necessidades básicas de toda população. Em nível empresarial, a prática da gestão ambiental aconteceu através da institucionalização da responsabilidade ambiental (ou social), ocorrida com maior ênfase no Brasil a partir da década de 1980. Na gestão pública, quer seja devido à carência de recursos técnicos, financeiros ou até mesmo em função da falta de pressão da população local, esse tipo de análise de comportamento não é levada em consideração na tomada de decisão sobre implantação da maior parte dos empreendimentos.

É cada vez maior a possibilidade de acesso a financiamentos que viabilizam a adoção de medidas voltadas ao desenvolvimento sustentável da cidade. Para que a gestão ambiental tenha uma representatividade efetiva junto às empresas e órgãos públicos, uma mudança na forma de análise dos custos ambientais deve ser feita tanto nos níveis micro e macroeconômico. Esta análise tem como objetivo principal mensurar, registrar e evidenciar ações que influenciam o meio ambiente, reconhecendo, assim, os custos relativos aos danos ambientais referentes às atividades e permitindo, até mesmo, o desenvolvimento de indicadores de desempenho ambiental (SILVA et al, 2002).

Também os aspectos relacionados ao processo de globalização da economia mundial, que vêm se manifestando de forma mais acelerada nos últimos anos, contribuem para o surgimento de normas e padronizações de gestão ambiental. Tais normas exigem cada vez mais que as empresas e os órgãos públicos adotem um comportamento frente às questões ambientais, caracterizado pela pró-atividade, com o uso de práticas que causem menores danos e menos impacto ao meio ambiente, adequando-se à legislação ambiental e estabelecendo uma relação de harmonia com a comunidade do entorno e população em geral (LUSTOSA, 2003).

Um Sistema de Gestão Ambiental (SGA) deve ser visto como uma estrutura que possibilite estabelecer uma política ambiental, com o adequado planejamento para se implantarem as ações e, ao mesmo tempo, permitir um monitoramento permanente. Esse monitoramento é realizado por meio da aplicação de indicadores que estabelecem as respectivas correções do sistema, atingindo seus objetivos em um processo de melhoria contínua.

\section{A valoração dos recursos naturais}

A análise econômica distingue, basicamente, dois grandes tipos de categorias de valores ambientais, que são os valores de uso e os 
valores de existência; da soma desses valores, resulta o valor econômico total de um determinado bem ou recurso natural.

Segundo Maia (2002), o valor de uso corresponde ao valor atribuído aos indivíduos pela participação numa determinada atividade, isto é, pelo uso direto, via extração ou consumo, ou ainda indireto de uma determinada amenidade ambiental: valor de uso total = valor para o utilizador + valor de opção.

O valor de opção diz respeito à disposição a pagar dos indivíduos para conservar um determinado recurso ou amenidade ambiental, manifestando a intenção de consumo direto ou indireto do bem ambiental que poderá ser usado no futuro e cuja substituição seria difícil (MAIA, 2002)

Já o valor de existência é aquele determinado a partir do momento em que os indivíduos obtêm benefícios pelo simples conhecimento de que determinada amenidade ambiental ou certa espécie existe, sem que haja a intenção de apreciá-las ou usá-las de alguma forma (DIXON; SHERMAN, 1991).

Com base nesses parâmetros, a Valoração Ambiental garante a sustentabilidade urbana como condição de equilíbrio entre a exploração de recursos e o desenvolvimento econômico, passando necessariamente por uma avaliação mais ampla de todos os processos que caracterizam os fatores de produção e mercado. De acordo com a definição de valor para um bem, um recurso ambiental, ou ainda um aspecto que represente uma amenidade ambiental, se conservado, pode ter o seu valor estimado como um benefício para a sociedade.
Não havendo essa conservação, o valor estimado desse bem passa a ser visto como um custo para a sociedade.

Além da dificuldade de se atribuírem valores a um recurso ou bem ambiental devido ao caráter subjetivo da valoração, também inexiste um padrão universal quando se trata de classificar os métodos de valoração existentes, o que, por sua vez, gera dificuldades ao empregá-los.

O Manual de Valoração Ambiental do Ministério do Meio Ambiente, por exemplo, classifica os métodos de valoração em métodos da função de produção (métodos da produtividade marginal e de mercados de bens substitutos) e métodos da função de demanda (métodos de mercado de bens complementares, preços hedônicos, do custo de viagem e método da valoração contingente). Pode-se, entretanto, distinguir de forma sintética duas categorias de métodos de valoração monetária do meio ambiente: os métodos indiretos e os métodos diretos de valoração, conforme evidenciado na Figura 1.

Mediante essa análise inicial, optou-se por realizar nesta pesquisa uma abordagem dos métodos diretos de valoração que consideram a disposição a pagar. Na escolha dos métodos analisados, também se consideraram os aspectos relativos ao objetivo proposto pela pesquisa e a eficiência do método para o caso específico, em função das informações disponíveis para a realização do estudo e das características da área objeto de intervenção.

Os métodos diretos de valoração estimam o valor econômico do recurso ambiental a partir da própria disposição a pagar da população

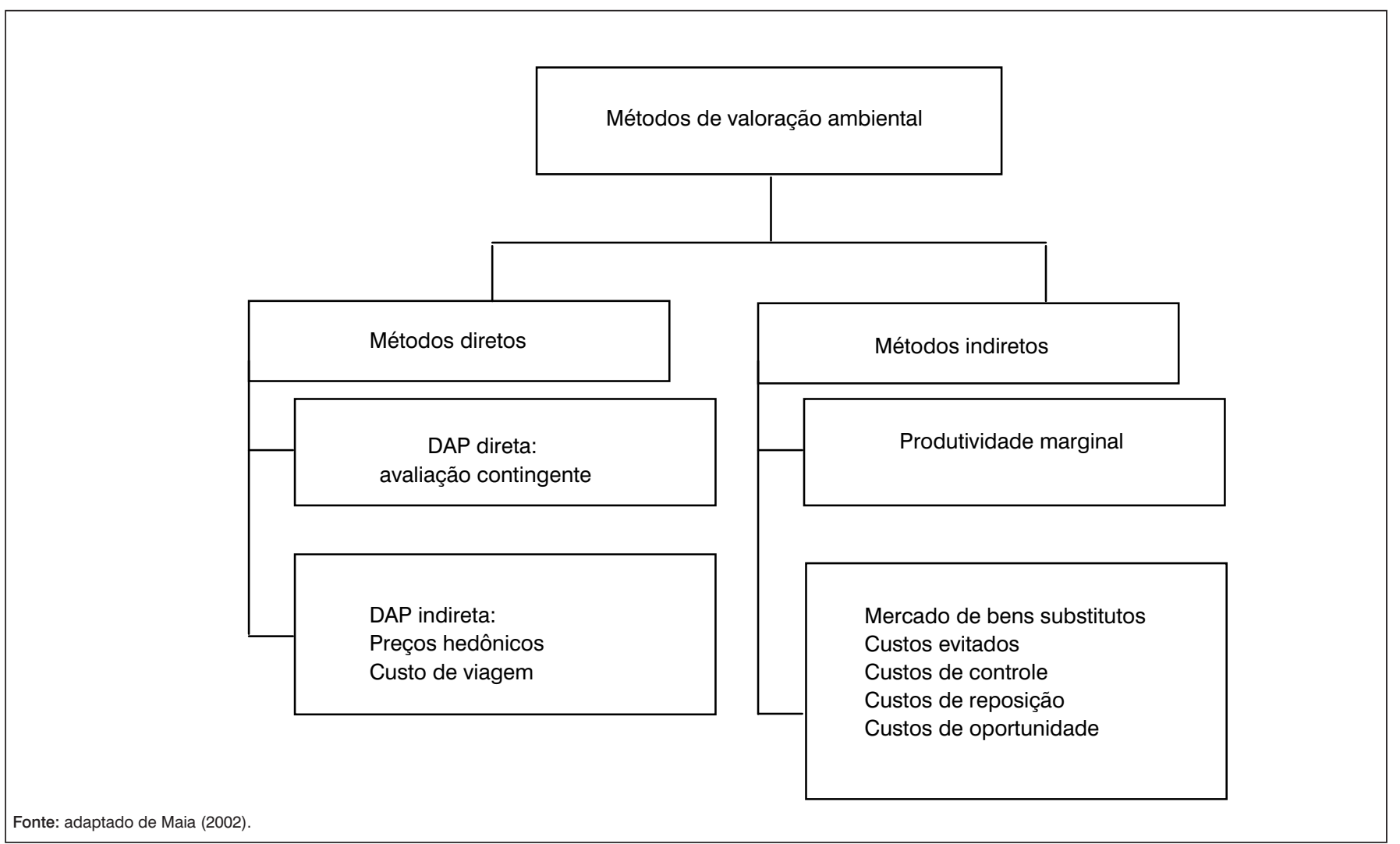

Figura 1 - Métodos de valoração ambiental 
para bens e serviços ambientais. Esses métodos partem do pressuposto que a variação da quantidade ou da qualidade do recurso ambiental afetará os padrões de bem-estar das pessoas. Com a variação de bem-estar, pode-se estimar a disposição a pagar das pessoas para evitar, ou a disposição a receber para aceitar as alterações do ambiente.

Inicialmente, o pesquisador terá de avaliar em quais das duas grandes categorias os referidos impactos estão inseridos: há aqueles que resultam em uma mudança mensurável na produção de algum bem ou serviço e aqueles que produzem mudança na qualidade ambiental (DIXON; SHERMAN, 1991) e, com base nessa classificação, deve-se definir qual abordagem de valoração será utilizada.

O Método da Avaliação Contingente (MAC), ou Método da Valoração Contingente (MVC), consiste em realizar entrevistas com os indivíduos a fim de que possam revelar sua valoração pessoal de bens usando um mercado hipotético (CUMMINGS; BROOKSHIRE; SCHULZE, 1986). Para tanto, geralmente faz-se a aplicação de questionários a uma amostra da população de usuários da amenidade ou recurso ambiental. Coletam-se informações referentes ao valor de uso, ao uso ativo da amenidade, ao valor de opção e ao valor de existência, que se referem ao uso passivo da amenidade. Ou seja, qual seria a disposição deles a pagar para usar essas amenidades no presente ou pela possibilidade de uso futuro ou, ainda, para garantir sua existência e, também, informações sobre atitudes e variáveis socioeconômicas (FARIA; NOGUEIRA, 2003).

Esse método, por suas características e peculiaridades, é o que se apresenta mais adequado como ferramenta a ser utilizada em função dos objetivos propostos pela pesquisa. Mesmo dando-se um enfoque hipotético, é possível captar valores de existência de bens e serviços ambientais e adaptá-los à maioria dos problemas ambientais.

Segundo Maia (2002), alguns autores argumentam que nas situações em que se torna necessário indicar um valor, a estimativa alcançada pelo MAC é a que mais se aproxima do verdadeiro valor econômico de um recurso natural.

Um dos exemplos clássicos de aplicação do MAC é a estimativa da disposição a pagar (DAP) levantada no caso do vazamento de quase 260 mil barris de petróleo do navio Exxon Valdez em Prince Willian Sound, Alasca, em 1989, além de ser utilizado por agentes financeiros internacionais como o Banco Mundial e o BID (Banco Interamericano de Desenvolvimento) para a estimativa de benefícios econômicos e estudo de viabilidade de projetos a serem financiados por essas instituições (MAIA, 2002).

\section{Metodologia}

\section{Localização e caracterização da área de estudo}

Situado no território brasileiro, o Município de Passo Fundo está localizado no Planalto Médio, no Norte do Estado do Rio Grande do Sul, a uma distância de $290 \mathrm{~km}$ da capital, Porto Alegre.
Possui uma população de 185.279 habitantes (Instituto Brasileiro de Geografia e Estatítico, 2005) com uma taxa de crescimento populacional de 1,67\% (2005) e elevado índice de urbanização, chegando a $97,21 \%$ da população concentrada na área urbana, ocasionado pelo crescimento desordenado ocorrido principalmente na década de 1970, o que gerou reflexos negativos ao meio ambiente, principalmente junto às áreas de preservação permanente de importantes mananciais hídricos.

Essa urbanização, de acordo com Tedesco, Kalil e Dal Moro (1996), gera alterações na estrutura social da cidade, tornando-se um reflexo do êxodo rural, da política de emancipação e do estímulo à criação de novos municípios, entre outros fatores. Essas condições, por sua vez, ocasionam uma profunda alteração no perfil econômico de Passo Fundo, que passa de uma economia baseada na produção agrícola para uma com base econômica na produção industrial, no comércio e na prestação de serviços

Para aplicação da metodologia de valoração ambiental, foi adotado o Método da Valoração Contingente, definindo-se como objeto de estudo uma área urbana considerada de risco e que apresenta uma série de problemas em relação aos aspectos de planejamento ambiental e ocupação do solo urbano. A área está localizada nas margens do Rio Passo Fundo, nas proximidades do aterro da atual malha da rede ferroviária da América Latina Logística (ALL) e da Estação Rodoviária, localizada no Bairro Cruzeiro. O local é constituído por um conjunto de áreas públicas e particulares, caracterizadas por ocupações irregulares feitas ao longo dos últimos 30 anos pela população mais carente cujo acesso às políticas públicas de desenvolvimento social e urbano é restrito.

Os questionários da DAP foram aplicados à população do entorno da área, como forma de obtenção de parâmetros de valores econômicos. Para tanto, considerou-se a atual divisão dos loteamentos do município (SEPLAN, 2004), sendo que a área a ser valorada está situada entre os loteamentos Vila Rodrigues, Vila Cruzeiro, Vila Popular e Jardim Primavera.

A Figura 2 localiza a área objeto de estudo na malha urbana do município de Passo Fundo em relação às principais vias públicas, bem como ao leito do Rio Passo Fundo.

A partir da delimitação do foco central da área objeto de estudo a ser valorada, foram arbitrados um raio mínimo, um raio intermediário e um raio máximo de distância para estabelecer a abrangência da coleta de dados. Essa delimitação da população a ser pesquisada junto ao entorno da área ocupada irregularmente, demonstrada na Figura 3, estabeleceu um alcance médio de 400 m, compreendido entre a Avenida Brasil, a Avenida Presidente Vargas e a Vila Petrópolis, obedecendo também aos setores censitários estabelecidos pelo Instituto Brasileiro de Geografia e Estatística (IBGE) e às três faixas de distância em relação à área de estudo.

Esses raios compreendem uma faixa com até 200 m de distância em relação à área a ser valorada, uma segunda faixa entre 200 e 400 m de distância e uma terceira faixa situada em posição superior, a $400 \mathrm{~m}$ 


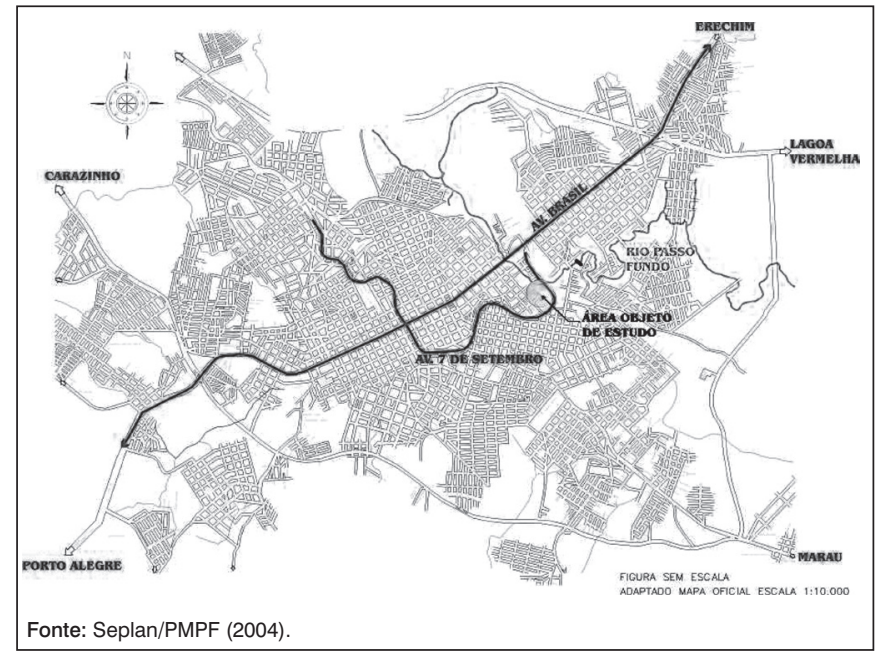

Figura 2 - Localização da área objeto de estudo na malha urbana do município, em relação às principais vias públicas e ao leito do Rio Passo Fundo

Tabela 1 - Dados habitacionais quantitativos sobre a área objeto de estudo

\begin{tabular}{lcc} 
Dados gerais & Unidade & Quantidade \\
Número de domicílios & Residências & 206 \\
Número de homens & Habitantes & 410 \\
Número de mulheres & Habitantes & 440 \\
Total geral de pessoas & Habitantes & 850 \\
Média geral de moradores por domicílio & Pessoas & 4,12 \\
\hline
\end{tabular}

Fonte: IBGE (2004)

de distância do local. A partir desses raios de abrangência, aplicaramse os questionários para a obtenção dos resultados da técnica de valoração econômica, através da DAP.

O IBGE (2004) apresentou dados relevantes, de acordo com a Tabela 1, relativos à população existente na área de ocupação definida como foco central de intervenção

$\mathrm{Na}$ etapa inicial, foi realizado um trabalho de campo com a visualização e caracterização dos impactos ambientais e de vizinhança existentes junto à área analisada, utilizando-se o método da avaliação pós-ocupação (walkthrough), observando-se os problemas mais relevantes em relação à ocupação e inserção na malha urbana da cidade, conforme as Figuras 4 e 5, permitindo, assim, um diagnóstico ambiental simplificado do local.

Tendo como base esse levantamento, foi possível estabelecer a amplitude do problema na área a ser recuperada e as diretrizes para formulação das hipóteses de recuperação da área degradada, apresentadas no questionário definitivo. Entre os impactos observados, é possível destacar: caracterização das moradias, infraestrutura urbana, mobilidade urbana, saneamento básico, vegetação nativa, mata ciliar e estrutura fundiária.

\section{Análise estatística}

Para o desenvolvimento da pesquisa, foram utilizadas análises quantitativas, por meio da elaboração e aplicação de questionários

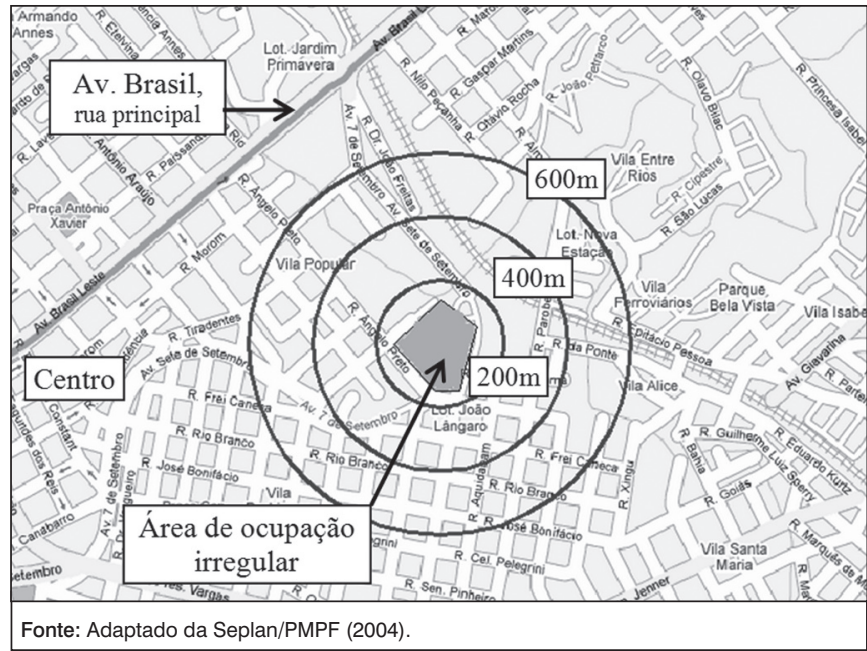

Figura 3 - Demarcação dos raios de abrangência dos questionários aplicados e o zoneamento urbano em relação ao entorno imediato à área objeto de estudo

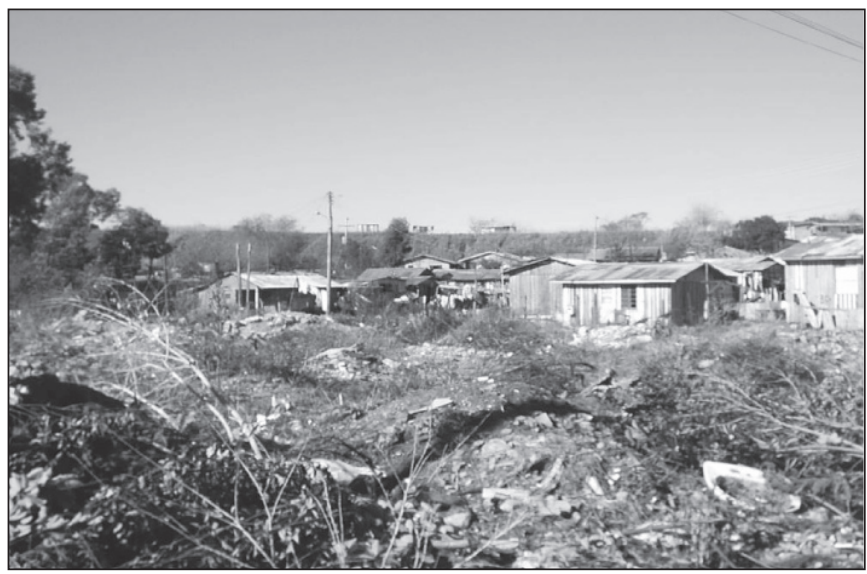

Figura 4 - Tipologias habitacionais e destino final incorreto do lixo existente junto à área objeto de estudo

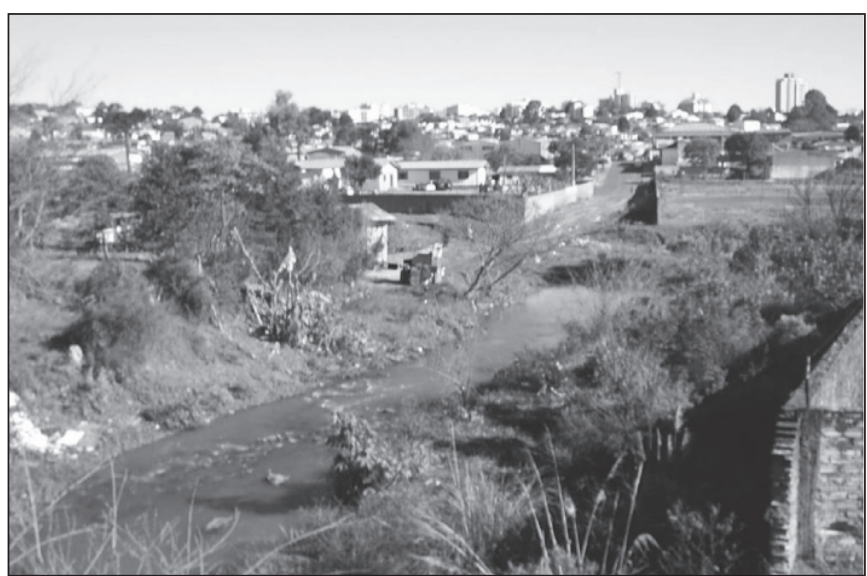

Figura 5 - Desmatamento e poluição do leito do Rio Passo Fundo observado junto à área: consequências da ocupação urbana

de forma aleatória junto à população definida como público alvo da pesquisa. Foram considerados, para efeito de população total a ser pesquisada, os moradores da totalidade dos domicílios ocupados de 
acordo com os dados censitários fornecidos pelo IBGE, o equivalente a 2.340 unidades, abrangendo uma população total de 7.842 habitantes. Mediante primeira análise estatística, considerando-se a DAP como uma variável importante do tipo binomial, assumindo valores de aceitação da oferta da DAP com uma resposta 'sim' ou de recusa dessa oferta com uma resposta 'não', definiu-se o tamanho da amostra para aplicação do questionário piloto em 49 residências durante os meses de maio e junho de 2004.

Esses questionários abordaram diretamente a disposição demonstrada pela população de pagar com vistas à hipótese de recuperação da área problemática, dados fundamentais para se determinar o tamanho definitivo da amostra e captar uma estimativa preliminar da distribuição da probabilidade de cada valor oferecido. Foram oferecidos os valores de R\$ 5,00; R\$ 10,00; R\$ 15,00; $\mathrm{R}$ \$ 20,00; R \$ 25,00 como opções de escolha para uma contribuição mensal pelo período de 12 meses. Obtiveram-se 33 respostas positivas, captando-se também a hipótese de recusa de pagamento pela recuperação da área, o que ocorreu 16 vezes, conforme a Tabela 2. Com os dados obtidos na amostragem piloto, realizou-se um novo cálculo estatístico para definição do tamanho da amostra final, juntamente com a elaboração do questionário definitivo a ser aplicado na população de entorno da área, de acordo com a técnica escolhida do MVC.

Nesse questionário definitivo, foram analisados aspectos culturais e socioeconômicos da população, seguindo parâmetros de modelos semelhantes aos questionários de avaliação pós-ocupação do ambiente construído observados por Ornstein e Romério (2004). Também foram levados em consideração os aspectos urbanos relevantes e os impactos ambientais existentes, sempre com o intuito de obter a disposição a pagar da população, tomando-se o cuidado de não entrevistar a população residente na área de ocupação irregular, para não influenciar os resultados obtidos.

Nessa fase da pesquisa, foram incluídas algumas variáveis qualitativas em relação ao local analisado, tais como: a sensibilidade ou não por parte da população com as questões ambientais; tempo de moradia no local; distância da residência até o local; impactos ambientais mais significativos e quatro hipóteses de recuperação do local. Esses questionamentos permitiram uma melhor interpretação dos dados obtidos na pesquisa em função das características da família ocupante

Tabela 2 - Distribuição dos dados coletados através do Método de Disposição a Pagar (DAP) na amostra piloto

$\begin{array}{lcccc}\text { DAP }(\mathbf{R} \$) & \text { Sim } & \text { Não } & p & n \\ 25,00 & 4 & 45 & 0,08 & 20 \\ 20,00 & 5 & 40 & 0,1 & 24 \\ 15,00 & 6 & 34 & 0,12 & 28 \\ 10,00 & 10 & 24 & 0,20 & 42 \\ 5,00 & 8 & 16 & 0,16 & 36 \\ \text { Total } & 33 & - & - & 150\end{array}$

da residência pesquisada e a sua percepção em relação aos problemas apontados, verificando-se, assim, a maior ou menor influência no resultado final da valoração.

Foram adotados, como parâmetros da amostragem definitiva, um limite de confiança de $90 \%$ com um coeficiente de confiança representado por $z \alpha / 2$ e equivalente a 1,64 , onde o tamanho da amostra será dado pela expressão:

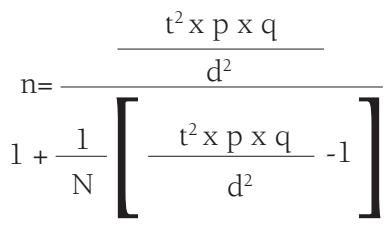

onde:

n: tamanho da amostra;

$\mathrm{N}$ : tamanho da população total;

t: $z \alpha / 2$, coeficiente de confiança;

p: probabilidade de sucesso;

q: probabilidade de fracasso;

d: precisão da estimativa.

A partir da definição do tamanho da amostra final em 150 questionários, também foi definido o número de 50 questionários a serem aplicados em cada faixa de distância pré-estabelecida. A primeira região, situada numa faixa de zero a 200 m de distância da área objeto de estudo; a segunda, situada numa faixa de 200 a 400 m de distância; a terceira, numa faixa situada a mais de 400 $\mathrm{m}$ de distância da área. Essa delimitação da aplicação dos questionários definitivos também teve como finalidade a aplicação da técnica de DAP, de modo a permitir uma melhor estratificação dos dados coletados.

Os valores apresentados para levantar a disposição a pagar por parte da população foram os mesmos apresentados no momento da aplicação do questionário da amostra piloto, ou seja, valores de $\mathrm{R} \$ 5,00 ; \mathrm{R} \$ 10,00 ; \mathrm{R} \$ 15,00 ; \mathrm{R} \$ 20,00$ e R $\$ 25,00$. Para facilitar a aplicação da DAP, foi utilizado o formato da questão do tipo referendo, no qual interroga-se o entrevistado sobre a disposição a pagar, podendo haver aceitação ou recusa da oferta. Para se obter um valor mais próximo da máxima DAP, foi adotado um formato derivado do referendo, denominado referendo dicotômico com iteração, no qual, após a oferta de um valor inicial intermediário ao entrevistado, é apresentado um valor maior em caso de resposta positiva, ou menor quando a resposta era negativa.

Com essa técnica de aplicação dos questionários da DAP, obtémse um aumento na eficiência das estimativas, pois as pessoas estão mais familiarizadas com esse formato por interagirem em situações semelhantes em transações comerciais, ao escolher, por exemplo, a compra ou não de determinado bem (MAIA, 2002). 


\section{Resultados e discussão}

\section{Caracterização geral da população da amostra pesquisada}

Nesta etapa, a população foi caracterizada considerando-se cinco aspectos: tempo de residência no local, sexo, idade, escolaridade e renda.

Quanto ao tempo de residência no local, 4\% da população tinha menos de um ano de residência no local e as demais faixas apresentaram certo equilíbrio, sendo a maioria (28\%) residente do local há 10 e 20 anos.

Quanto ao sexo, a maioria dos entrevistados era do sexo feminino (54\%) e com idade entre 40 e 49 anos (31\%). Ainda quanto à idade, observou-se que as faixas de menor ocorrência dos entrevistados foram até 18 anos (3\%) e acima de 60 anos (5\%).

Referente à escolaridade, a maioria das pessoas (38\%) possuía o ensino médio completo e, na sequência, ensino superior completo (27\%) e superior incompleto (19\%). A faixa de renda das famílias entrevistadas variou entre cinco e sete salários mínimos (29\%) e, logo seguida, de três a cinco salários mínimos (25\%), existindo ainda um equilíbrio na faixa acima de dez salários mínimos (17\%) e de sete a dez salários mínimos (16\%).

\section{Resultados gerais da amostra pesquisada: impactos ambientais}

Nesta fase, analisaram-se os resultados relativos à maior ou menor significância dos impactos ambientais encontrados na primeira fase da pesquisa. Esses impactos foram apresentados à população pesquisada com o objetivo de se verificarem a preocupação do entrevistado com as questões ambientais e os impactos considerados mais significativos pelos entrevistados, mediante a fixação de uma escala de valor de 1 a 7 , sendo 1 o impacto considerado de maior importância e 7 o de menor importância.

Considerando as diversas faixas de distância estabelecidas pela pesquisa, demonstra-se que a grande maioria da população entrevistada possui um elevado índice de preocupação com as questões ambientais, independentemente da distância da residência do entrevistado até o local pesquisado. Essa preocupação é representada pelos percentuais não inferiores a $80 \%$, apesar da queda nesse percentual em função do maior afastamento da área pesquisada. 70\% da população afirma ter conhecimento do problema específico daquela área. Isso demonstra que há uma maior conscientização da população, ou ainda, um ponto de viés de pesquisa gerado pelo receio do entrevistado em demonstrar a falta de interesse pelas questões levantadas.

Em relação aos impactos ambientais mais significativos, representados na Figura 6, pelo menos dois impactos foram considerados relevantes pelo total da população entrevistada.

Esses impactos referem-se especificamente à mobilidade urbana devido ao estreitamento viário existente junto na ponte sobre o Rio Passo Fundo, localizada na Avenida Sete de Setembro, prolongamento da Rua Duque de Caxias, e à caracterização das moradias devido ao risco permanente de inundação existente na área objeto de estudo. Um terceiro impacto bastante citado pela população entrevistada foi referente à vegetação nativa e mata ciliar, graças ao desmatamento das margens do leito do Rio Passo Fundo, considerado o mais significativo pela população residente nas faixas que variam de 200 a 400 m de distância da área.

Esse impacto, entretanto, quando a população entrevistada reside numa distância superior a $400 \mathrm{~m}$ do local, é superado em grau de

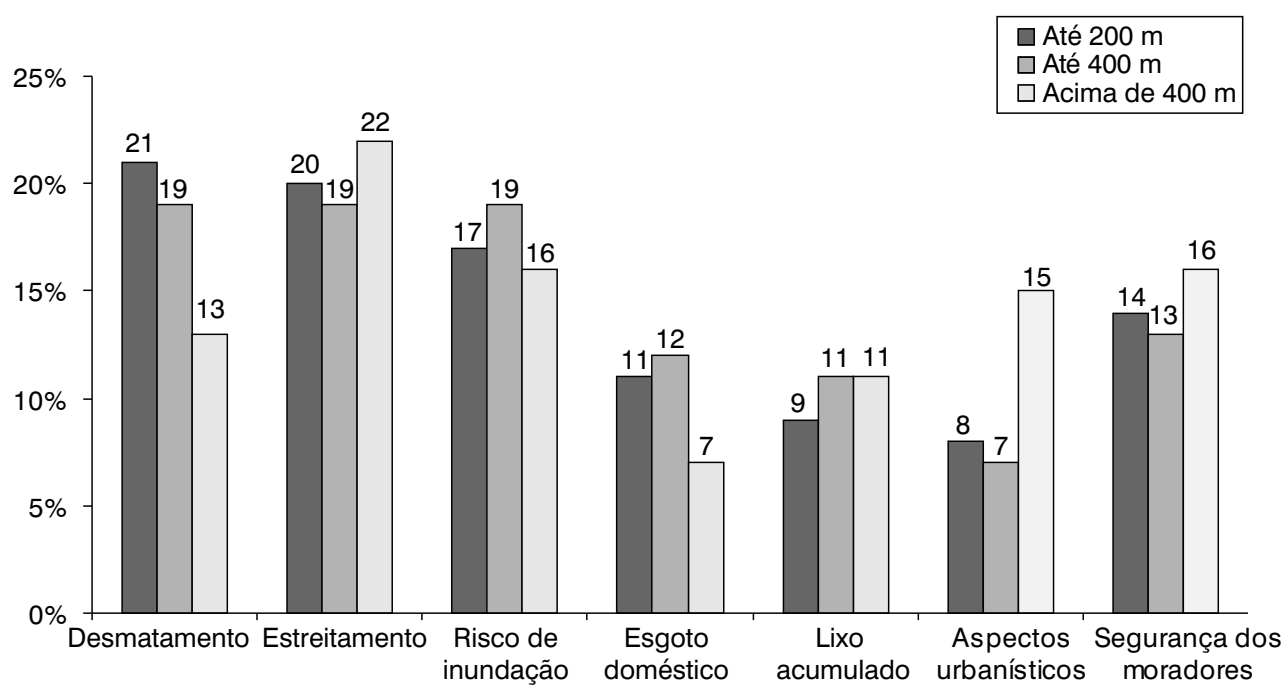

Figura 6 - Impactos ambientais mais significativos registrados pelos entrevistados nos três raios de abrangência das entrevistas 
importância, sendo a maior relevância atribuída aos aspectos relativos à segurança dos moradores e às questões urbanísticas da área.

\section{Resultados gerais da amostra pesquisada: aspectos urbanísticos}

Nesta etapa de análise dos dados obtidos, são apresentados os resultados relativos à necessidade ou não de recuperação da área objeto de estudo como forma de diminuir os impactos ambientais em função dos problemas encontrados, os seus reflexos na urbanização do local e, dentre as alternativas de recuperação apresentadas, qual é a mais adequada para a população. Essas propostas de recuperação foram apresentadas à população pesquisada com o objetivo de verificar a preferência do entrevistado, mediante a fixação de uma escala de valor com variação numérica de 1 a 4 , adotando-se o valor 1 para a proposta mais adequada e 4 para a menos adequada.

A população entrevistada considera importante a necessidade de algum tipo de intervenção na área para sua recuperação, tendo sido registrado um índice de aceitação superior a 96\%, independentemente da distância da moradia do entrevistado em relação ao local pesquisado, mas com um pequeno decréscimo nesse índice em função de uma maior distância entre a moradia e a área objeto de estudo. Destaca-se também o percentual de $100 \%$ da população entrevistada na faixa de até $200 \mathrm{~m}$ da área objeto de estudo no que se refere à necessidade de intervenção e melhorias no local.

Quanto ao tipo de intervenção a ser realizada, conforme apresentado na Figura 7, existe uma preferência por alguma das propostas apresentadas. Existe um predomínio da alternativa de recuperação que mantém as famílias no local, mediante a urbanização adequada da área, para a população residente nas proximidades da área (faixa de distância até 200 m), com um percentual de 30\%. Enquanto a população residente em áreas mais afastadas do local (faixas de distância entre 200 e 400 m e acima de $400 \mathrm{~m}$ ) prefere a retirada total das famílias com a recuperação do local e a manutenção da área como área verde de preservação dos mananciais hídricos, com um percentual de 29\% em ambas as faixas.

\section{Resultados gerais da amostra pesquisada: método DAP}

Nesta última etapa de análise dos dados, são apresentados os resultados relativos à DAP encontrada mediante a aplicação da técnica de valoração econômica, por meio do Método da Avaliação Contingente, tendo como base da formulação do questionário todos os aspectos ambientais e urbanísticos levantados na primeira fase da pesquisa.

Os valores apresentados à população pesquisada, com o objetivo de verificar a disposição a pagar para a recuperação da área objeto de estudos, refletem um valor econômico diretamente relacionado ao bem-estar da população. Numa primeira alternativa mediante um questionamento direto da DAP, considerando todos os aspectos citados anteriormente, e numa segunda alternativa na sequência da entrevista, vinculando a DAP a uma valorização do imóvel.

$O$ valor obtido na DAP pode ter uma relação com a execução efetiva de uma das alternativas de intervenção propostas, ou ainda, estar relacionado às condições socioeconômicas, fatores culturais, tempo de moradia no local e grau de importância atribuído aos impactos ambientais pelo entrevistado.

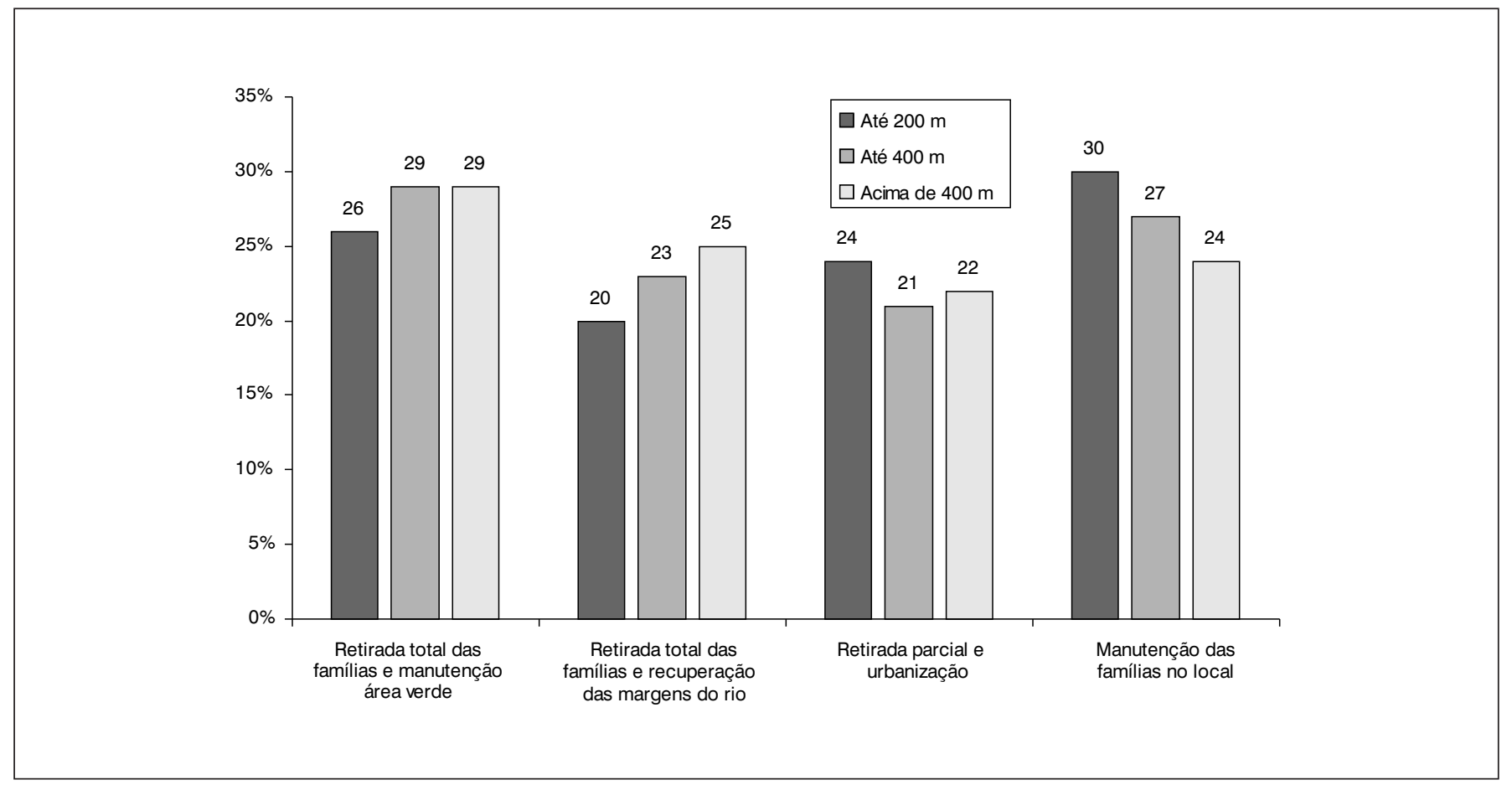

Figura 7 - Preferência quanto às propostas de intervenção apresentadas aos entrevistados nos três raios de abrangência da área de estudo 
Analisando-se os dados relativos à disposição a pagar por parte da população entrevistada de uma forma comparativa, foi estabelecida uma relação entre o valor monetário dessa disposição a pagar e a alternativa de valorização do imóvel de propriedade do entrevistado. Porém, isso é significativo se for levada em consideração a sua distância em relação à área objeto de estudo. A Figura 8 demonstra uma elevada indisposição a pagar por parte da população em geral num primeiro momento, exceto na faixa da população entrevistada com distância superior aos $400 \mathrm{~m}$ do local, em que a disposição inicial supera a parcela de entrevistados que respondeu não. Isso se reflete, de um modo geral, em valores baixos a serem pagos mediante a possibilidade de recuperação do local e num elevado grau de incerteza da resposta.

A partir do momento em que é ponderada, junto ao entrevistado, a alternativa de valorização do seu imóvel, com uma possível recuperação e melhoria da área, eleva-se significativamente o percentual da população entrevistada que estaria disposta a pagar por ela, principalmente nas faixas mais próximas do local, como apresentado na Figura 9. Essa possibilidade acaba por refletir no aumento do valor econômico da disposição a pagar, por parte da população, e no grau de certeza dessa contribuição.

Com os dados obtidos, calcula-se a máxima disposição a pagar pela recuperação da área objeto de estudo, encontrando-se um valor médio diferente para cada faixa de distância da residência do entrevistado em relação ao local da possível intervenção, além de uma média geral, levando-se em consideração toda a população pesquisada.

De acordo com a Tabela 3, os valores da média da DAP obtidos na primeira alternativa são aqueles em que os valores são oferecidos ao entrevistado na primeira parte do questionário de valoração, sem qualquer referência a um possível benefício ao entrevistado com a intervenção proposta para a área.

Os valores obtidos na segunda alternativa referem-se àqueles em que é sugerida ao entrevistado uma possível valorização do seu imóvel em virtude da implantação efetiva de alguma das intervenções propostas para recuperação do local.

Adotando-se a média geral, obtida na primeira alternativa, equivalente a R\$4,63, e na segunda alternativa, equivalente a R \$ 14,00, e considerando-se o número de domicílios ocupados na região delimitada pela pesquisa, que totalizam 2.340 unidades, obtém-se um valor mensal de contribuição da DAP que varia de $\mathrm{R} \$ 10.834,20$ a $\mathrm{R} \$$ $32.760,00$, o que corresponderia, ao longo do período de contribuição de 12 meses estipulado pela pesquisa, a um valor total da DAP variável entre $\mathrm{R} \$ 130.010,40$ a $\mathrm{R} \$ 393.120,00$

O valor total obtido na DAP demonstra o potencial de recursos que a população estaria disposta a desembolsar como forma de auxílio ao gestor público para custear as despesas de recuperação da área mediante a escolha da opção apontada como a mais adequada. Com a utilização de cálculos de atualização monetária, os valores encontrados podem ser corrigidos de forma a se obter o valor real da DAP em função da taxa de juros aplicada pelo mercado durante o período de contribuição. Fica demonstrado que o valor da contribuição aumenta significativamente quando se expõe ao entrevistado a possibilidade de valorização do seu imóvel com a intervenção a ser realizada.

Salienta-se que esse valor representa a disposição a pagar de uma pequena parcela da população total do município de Passo Fundo, em razão da faixa delimitada para realização da pesquisa

Tabela 3 - Relação da média de Disposição a Pagar quantificada em valores monetários

\begin{tabular}{lcccc}
\hline Descrição & Distância & $\begin{array}{c}\text { Entre 200 } \\
\text { e 400 m }\end{array}$ & $\begin{array}{c}\text { Mais de } \\
400 \mathrm{~m}\end{array}$ & Geral \\
\hline 1a alternativa & 3,00 & 3,90 & 7,00 & 4,63 \\
\hline Desvio padrão & 4,69 & 5,83 & 6,28 & 5,96 \\
\hline 2a alternativa & 15,70 & 14,90 & 11,40 & 14,00 \\
\hline Desvio padrão & 5,76 & 6,67 & 6,07 & 6,11
\end{tabular}

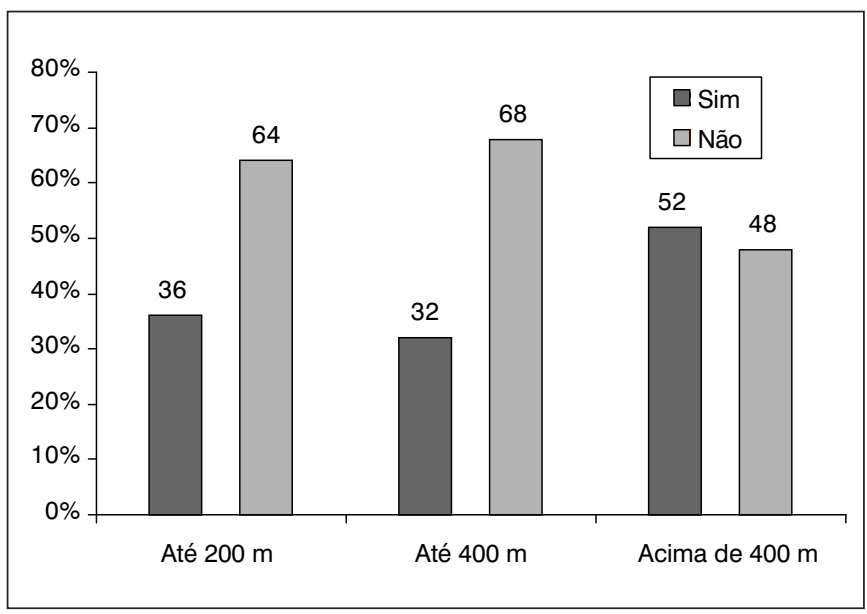

Figura 8 - Disposição a pagar dos entrevistados sem considerar a valorização do imóvel

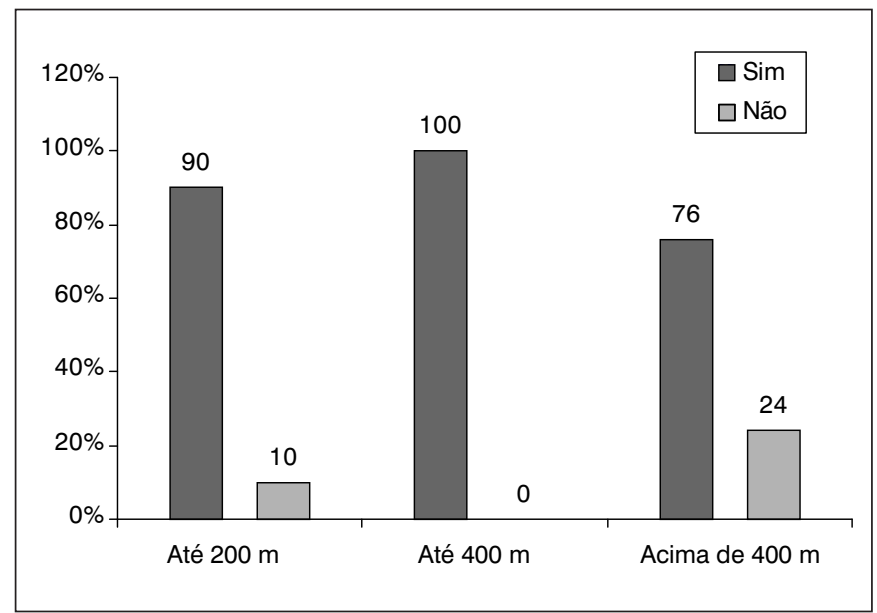

Figura 9 - Disposição a pagar dos entrevistados considerando-se a valorização do imóvel 
Traduz, ainda, uma pequena parcela dos benefícios a serem gerados pela intervenção urbanística e recuperação dos danos ambientais existentes. Embora esses aspectos devam ser observados, os valores obtidos podem ser adotados como uma referência a ser considerada pelo gestor público para a viabilização de um projeto de recuperação da área estudada.

\section{Conclusões}

Durante a realização da pesquisa, foi possível constatar que existe, hoje, por parte da sociedade em geral, uma maior conscientização e preocupação com as questões ambientais que envolvem as comunidades. Isso é decorrente de um maior nível de informação disponível a todos, além do contato diário com os problemas urbanos relacionados ao meio ambiente e as graves consequências geradas por fatores que influenciam diretamente o aspecto econômico e a sustentabilidade de várias atividades.

Em relação aos impactos ambientais, observa-se, por parte dos entrevistados de todas as faixas de distância estabelecidas pela pesquisa, uma forte preocupação com a degradação da paisagem ambiental urbana. Isso ocorre em função da maior visibilidade desses problemas em relação aos demais impactos constatados, visto que estes se localizam no entorno da área e junto às vias públicas, o que justificaria também a preocupação significativa com a segurança dos moradores de uma forma geral.
Ao aplicar a técnica da valoração econômica na busca de estimar qual o valor econômico do bem a ser recuperado, os entrevistados tomaram conhecimento de uma ferramenta de pesquisa inovadora e que procura atribuir um valor financeiro a algo subjetivo. Ao abordar o tema com o questionamento da disponibilidade a pagar pela recuperação de um bem ambiental, surgem dúvidas relativas ao valor do ar que se respira, da vegetação próxima à residência de cada um e, ainda, da preservação ou recuperação de determinado rio ou córrego da cidade.

A metodologia utilizada para a análise dos problemas existentes em determinado objeto de estudo permite a identificação das preferências e expectativas da população. Esse procedimento proporciona, assim, um maior envolvimento da população ao longo do processo de elaboração da proposta definitiva de recuperação do local, importante fator quando se trata de empreendimentos relacionados à ocupação do solo urbano. Dessa forma, reforça-se a fundamentação teórica que aponta a valoração econômica como um importante instrumento de auxílio ao processo de tomada de decisões no momento da definição de políticas públicas ambientais e de desenvolvimento sustentável.

Portanto, a metodologia utilizada demonstrou a viabilidade de aplicação considerando as diferentes condicionantes ambientais, notadamente no que se refere à valoração de um passivo ambiental, e fazendo com que os resultados obtidos demonstrem diferentes graus de sensibilização e importância dos diferentes impactos ambientais para a população estudada.

\section{Referências}

CUMMINGS, R.G.; BROOKSHIRE, D.S.; SCHULZE, W.D. (Ed.). Valuing environmental goods: an assessment of the contingent valuation method. Totowa: Rowman \& Allanheld, 1986.

DIXON, J.A.; SHERMAN, P.B. Economics of protected areas: a new look at benefits and costs. Washington: Island Press, 1991.

FARIA, R.C.; NOGUEIRA, J.M. Método de valoração contingente: aspectos teóricos e testes empíricos. Disponível em: www.unb.br/face/ eco/nepama2k/NEPAMA004.doc. Acesso em: 25 nov. 2003.

Instituto Brasileiro de Geografia e Estatííisca. Índices estatísticos sobre demografia, clima, faixa etária, etc., 2005.

Índices estatísticos sobre demografia, clima, faixa etária, etc., 2004.

LUSTOSA, M.C. Industrialização, meio ambiente, inovação e competitividade. In: MAY, P.; LUSTOSA, C.; VINHA, V. (Org.). Economia do meio ambiente. Rio de Janeiro: Elsevier, 2003. p. 155-72.

MAIA, A.G. Valoração de recursos ambientais. Dissertação (Mestrado em Economia) - Instituto de Economia da Unicamp, Campinas, São Paulo, 2002.
MAIMON, D. Passaporte verde: gestão ambiental e competitividade. Rio de Janeiro: Qualitymark, 1996

ORNSTEIN, S.; ROMÉRIO, M. Avaliação pós-ocupação do ambiente construído. São Paulo: Edusp, 2004.

ROSSETTO, A.M. Proposta de um sistema integrado de gestão do ambiente urbano (SIGAU) para o desenvolvimento sustentável de cidades. Tese (Doutorado) - UFSC, Florianópolis, 2003.

SEPLAN. Mapas oficiais do perímetro urbano de Passo Fundo. Secretaria Municipal de Planejamento da Prefeitura Municipal de Passo Fundo. Passo Fundo, 2004

SILVA, M.A.S. et al. Custos ambientais: uma abordagem sob o enfoque das contas nacionais (macro) e sob a visão empresarial (micro). In: VIII CONGRESSO BRASILEIRO DE CUSTOS, Unisinos, Rio Grande do Sul, de 3 a 5 de outubro de 2002.

TEDESCO, J.C.; KALIL, R.M.L.; DAL MORO, S.M. Urbanização, exclusão e resistência: estudos sobre o processo de urbanização na região de Passo Fundo. Passo Fundo: EDIUPF, 1996. 